\title{
Irradiation-assisted electrochemical processes for the removal of persistent organic pollutants from wastewater
}

\author{
María J. Martín de Vidales, Cristina Sáez*, José F. Pérez, Salvador Cotillas, Javier \\ Llanos, Pablo Cañizares, Manuel A. Rodrigo. \\ Department of Chemical Engineering. Enrique Costa Building. Campus Universitario \\ s/n. 13071 Ciudad Real. Spain
}

\begin{abstract}
This work focused on the removal of Persistent Organic Pollutants (POPs) from wastewater using irradiation-assisted electrochemical technologies, i.e., sonoelectrolysis, photoelectrolysis and sono-photoelectrolysis. Single-irradiation processes (sonolysis and photolysis) and electrochemical oxidation using conductive diamond anodes (current density of $30 \mathrm{~mA} \mathrm{~cm}^{-2}$ ) were also evaluated for comparison. Three POPs with different molecular structures (sulfamethoxazole, metoprolol and caffeine, initial concentration of $100 \mathrm{mg} \mathrm{dm}^{-3}$ ) were studied to evaluate the robustness of the selected technologies and the oxidation mechanisms involved in each case. Results show that the single application of the irradiation technologies led to the removal of only a small amount of POPs and no mineralisation, with the nature of the pollutant showing a marked effect; the opposite was observed for the single application of Conductive Diamond Electrochemical Oxidation (CDEO), which is a highly robust and efficient technology for the degradation of all types of POPs. Sonoelectrolysis, photoelectrolysis and sono-photoelectrolysis processes (ultrasound conditions: $200 \mathrm{~W}$, ultraviolet conditions: $254 \mathrm{~nm}, 4 \mathrm{~W}$ ) may show synergistic, antagonistic or nil effects with respect to a single electrochemical oxidation event, depending on the nature of the treated molecule. The differences observed may be related to the different chemical
\end{abstract}


nature of the organic species studied, indicating an important role of mediated oxidation processes, which may be enhanced with ultrasounds and ultraviolet radiation techniques.

Key Words: Electrochemical oxidation, sonoelectrolysis, photoelectrolysis, sulfamethoxazole, metoprolol, caffeine.

${ }^{*}$ Corresponding author: Tel.: +34 902204100 ext. 6708; Fax: +34 926295256; e-mail: Cristina.Saez@uclm.es 


\section{Introduction}

The occurrence of Persistent Organic Pollutants (POPs) in the aquatic environment is an issue that affects an increasing number of people in today's society due to the serious environmental and health problems posed by these substances. These pollutants cannot be removed efficiently by conventional wastewater treatment methods $[1,2]$. Thus, it is necessary to find a suitable technology for the removal of POPs from waters and wastewaters. In this context, electrochemical oxidation presents desirable features for the treatment of POPs, such as high efficiency, robustness and environmental compatibility [3-11]. Furthermore, to improve the efficiency of this process, in which typically POPs concentrations are very low, scientific efforts have been focused on the combination of anodic oxidation with other processes such as oxidant production. In this respect, ultraviolet light ultraviolet (UV) or ultrasonic (US) radiation [12-23] can help expand the applicability of electrochemical technology used to treat concentrated wastewater (typically industrial effluents) to the removal of organics in diluted flows (such as the removal of POPs from urban treated wastewater) [24,25].

The literature $[12,20,22,13,23,26-28]$ indicates that the combined use of an US generator and single electrochemical oxidation can help improve mass transfer to anodic surfaces, promote the decomposition of water producing hydroxyl radicals and favour electrohydraulic cavitation.

On the other hand, synergistic effects of the combination of photo irradiation and the electrochemical process, with greater removal efficiency over the expected separate contributions, was observed in recent studies [28,29]. Electrochemical oxidation of organic with conductive-diamond anodes is not limited by electrode processes, an 
enhancement in the efficiency is only expected if homogeneous catalytic processes are promoted $[30,16,18,17,14]$. As is well known, the use of conductive diamond anodes allows for the production of many types of oxidants [31-35], including $\mathrm{H}_{2} \mathrm{O}_{2}, \mathrm{O}_{3}$ (Eqs. 1 and 2) and oxidants generated by the anodic oxidation of inorganic electrolytes present in media (Eqs. 3 and 4) during the electrochemical oxidation of wastewater (peroxosulphates, chlorine, etc.). In this point, recent studies have shown that most of these oxidants should be activated to promote mediated oxidation [36].

$$
\begin{aligned}
& \mathrm{O}_{2}+\bullet \mathrm{O}_{3} \mathrm{O}_{3} \\
& \mathrm{H}_{2} \mathrm{O}+1 / 2 \mathrm{O}_{2} \rightarrow \mathrm{H}_{2} \mathrm{O}_{2} \\
& \mathrm{SO}_{4}{ }^{2-} \rightarrow \mathrm{S}_{2} \mathrm{O}_{8}{ }^{2-}+2 \mathrm{e}^{-} \\
& \mathrm{Cl}^{-}+\mathrm{H}_{2} \mathrm{O} \rightarrow \mathrm{HClO}+\mathrm{H}^{+}+2 \mathrm{e}^{-}
\end{aligned}
$$

In this respect, it is expected that UV light irradiation can promote the homogeneous photo-activation of electrogenerated oxidants and improve the efficiency of single electrochemical oxidation (Eqs. 5 and 6). Thus, in photoelectrolytic processes, the effect of these activated radicals can be extended to the bulk, in spite of their short life time. In addition, it is important to highlight the generation of hydroxyl radicals by action of UV light with $\mathrm{H}_{2} \mathrm{O}_{2}$ and $\mathrm{O}_{3}$ species, according to reactions 7 and 8:

$$
\begin{aligned}
& \mathrm{S}_{2} \mathrm{O}_{8}{ }^{2-} \stackrel{\mathrm{hv}}{\longrightarrow} 2\left(\mathrm{SO}_{4}^{-}\right)^{\bullet} \\
& \mathrm{Cl}^{-} \stackrel{\mathrm{hv}}{\longrightarrow} \mathrm{Cl}^{\bullet}+\mathrm{O}^{-\bullet} \\
& \mathrm{H}_{2} \mathrm{O}_{2} \stackrel{\mathrm{hv}}{\longrightarrow} 2{ }^{\bullet} \mathrm{OH} \\
& \mathrm{H}_{2} \mathrm{O}_{2}+\mathrm{O}_{3} \stackrel{\text { hv }}{\longrightarrow} 2{ }^{\bullet} \mathrm{OH}+\mathrm{O}_{2}
\end{aligned}
$$


Opposite to single electrolytic process, the effect of these radicals can be extended to the bulk in a photoelectrolytic process, because in spite of their short lifetime, they can be produced in the bulk by decomposition of more stable oxidants. However, direct action of UV radiation is not taking into account due to high refractoriness of persistent pollutants that hinders its degradation.

Thus, the aim of this work was to study the combined use of Conductive Diamond Electrochemical Oxidation (CDEO) and UV light and/or US irradiation in the treatment of wastewater polluted with POPs. To shed light on the effect of the type of pollutant treated, three POPs with very different chemical structures were studied: sulfamethoxazole $\left(\mathrm{C}_{10} \mathrm{H}_{11} \mathrm{~N}_{3} \mathrm{O}_{3} \mathrm{~S}\right.$, an anti-bacterial sulphonamide and a very useful antibiotic), metoprolol $\left(\mathrm{C}_{15} \mathrm{H}_{25} \mathrm{NO}_{3}\right.$, a $\beta$-blocker used alone or in combination with other medications to treat high blood pressure $)$ and caffeine $\left(\mathrm{C}_{8} \mathrm{H}_{10} \mathrm{~N}_{4} \mathrm{O}_{2}\right.$, a widely consumed stimulant).

\section{Materials and methods}

\subsection{Chemicals}

Sulfamethoxazole (SMX), metoprolol tartrate salt (2:1) and caffeine (analytical grade, > 99\% purity) were supplied by Sigma-Aldrich Laborchemikalien GmbH (Steinheim, Germany). Analytical grade anhydrous sodium sulphate, used as a supporting electrolyte, was purchased from Fluka. All solutions were prepared with high-purity water with a resistivity $>18 \mathrm{M} \Omega \mathrm{cm}$ at $25^{\circ} \mathrm{C}$ obtained from a Millipore Milli-Q system. Sulphuric acid and sodium hydroxide, used to adjust the solution $\mathrm{pH}$, were of analytical grade and supplied by Panreac Química S.A. (Barcelona, Spain). 


\subsection{Analytical procedures}

The Total Organic Carbon (TOC) was monitored using a Multi N/C 3100 Analytik Jena analyser. Measurements of $\mathrm{pH}$ and conductivity were carried out with an InoLab WTW pH-meter and a GLP 31 Crison conductimeter, respectively. The concentrations of the compounds were quantified by HPLC (Agilent 1100 series). The detection wavelength used to detect POPs depends on the compound studied (SMX: 245 nm, metoprolol: 223 nm, caffeine: $205 \mathrm{~nm}$ ). For the HPLC measurements, the column temperature was set to $25{ }^{\circ} \mathrm{C}$ and the injection volume was set to $50 \mu \mathrm{L}$. The analytical column used was a Phenomenex Gemini $5 \mu \mathrm{m} \mathrm{C18} \mathrm{column,} \mathrm{and} \mathrm{the} \mathrm{solvent} \mathrm{solution} \mathrm{was} \mathrm{a} \mathrm{mixture} \mathrm{of} 25$ $\mathrm{mM}$ of formic acid and acetonitrile (linear gradient chromatographic elution was performed from 10 to $100 \%$ acetonitrile in $40 \mathrm{~min}$ ). Samples extracted from electrolysed solutions were filtered with $0.20 \mu \mathrm{m}$ Nylon filters before analysis. Moreover, the acid intermediates formed during the experiments were detected at a wavelength of $190 \mathrm{~nm}$ using a SUPELCOGELTM H Carbohydrate Column from Sigma-Aldrich, and dilute $\mathrm{H}_{3} \mathrm{PO}_{4}(0.022 \mathrm{M})$ was used as the solvent.

\subsection{Electrochemical cells and US/UV equipment}

Electrolyses were carried out in a single-compartment electrochemical flow cell operated in batch mode [37]. Conductive diamond electrodes (p-Si-boron-doped diamond) were used as anodes and stainless steel (AISI 304) as a cathode. Both types of electrodes were circular (100 mm diameter) with a geometric area of $78 \mathrm{~cm}^{2}$ and an electrode gap of $2 \mathrm{~mm}$. Boron-doped diamond films were provided by Adamant Technologies (Neuchatel, Switzerland), synthesised by the hot filament chemical vapour deposition technique (HF CVD) on single-crystal p-type Si $<100>$ wafers (0.1 
$\Omega \mathrm{cm}$, Siltronix). The main properties of the diamond coatings used in this work were an $\mathrm{sp}^{3} / \mathrm{sp}^{2}$ ratio of 226 and a thickness of $3 \mu \mathrm{m}$.

Irradiated experiments were carried out in the electrolysis set up and using the same fluid-dynamic conditions. To do this, it was equipped with an ultrasound source (UP200S ultrasound horn, Hielscher Ultrasonics GmbH, equipped with a titanium glass horn measuring $40 \mathrm{~mm}$ in diameter and $100 \mathrm{~mm}$ in length) and an UV lamp (Vilber Lourmat filtered lamp,VL-215.MC, with a power of $4 \mathrm{~W}$ ). The ultrasound generator irradiates energy into an auxiliary tank, while UV lamp is located just in front of the electrochemical cell and irradiates directly to the anodic surface to promote the activation of the oxidants formed electrochemically (a quartz plate and a lattice cathode of stainless steel are used). Figure 1 shows the experimental system used (the onset of the figure shows in detail the UV reactor).

\subsection{Experimental procedures}

Bench-scale electrolyses of $1000 \mathrm{~cm}^{3}$ of wastewater were carried out under galvanostatic conditions. The current density employed was $30 \mathrm{~mA} \mathrm{~cm}{ }^{-2}$. The cell voltage did not vary during electrolysis, indicating that the conductive diamond layers did not undergo appreciable deterioration or passivation phenomena. Prior to use in galvanostatic electrolysis assays, the electrode was polarised for $10 \mathrm{~min}$ in a $0.035 \mathrm{M}$ $\mathrm{Na}_{2} \mathrm{SO}_{4}$ solution at $15 \mathrm{~mA} \mathrm{~cm}{ }^{-2}$ to remove any impurities from its surface. In USirradiated technologies, the ultrasound horn irradiated a continuous ultrasonic radiation at a frequency $24 \mathrm{kHz}$ and a maximum ultrasonic power of $200 \mathrm{~W}$. In UV-irradiated technologies, the wavelength used was $254 \mathrm{~nm}$ (UV-C). In single photolysis and sonolysis essays, the power supply was disconnected 
The wastewater was stored in a glass tank and circulated through the electrolytic cell using a centrifugal pump (flow rate $\left.21.4 \mathrm{dm}^{3} \mathrm{~h}^{-1}\right)$. The mass transfer coefficient $\left(\mathrm{K}_{\mathrm{m}}\right)$ of the electrochemical cell within the fluid dynamic conditions used (21.4 $\left.\mathrm{dm}^{3} \mathrm{~h}^{-1}, 298 \mathrm{~K}\right)$ is $8 \cdot 10^{-6} \mathrm{~m} \mathrm{~s}^{-1}$, calculated from a standard $\mathrm{Fe}(\mathrm{CN})_{6}{ }^{3+} / \mathrm{Fe}(\mathrm{CN})_{6}{ }^{2+}$ current limit test [38]. A heat exchanger coupled to a controlled thermostatic bath (Digiterm 100, JP Selecta, Barcelona, Spain) was used to maintain the temperature at the desired set point $\left(25^{\circ} \mathrm{C}\right)$.

\section{Results and discussion}

Figure 2 shows the changes in the pollutant concentration and TOC during the treatment of synthetic wastewater by photolysis (part a), sonolysis (part b) and CDEO (part c). The three types of synthetic wastewater tested consisted of a solution of $100 \mathrm{mg} \mathrm{dm}^{-3}$ of sulfamethoxazole (SMX), metoprolol, or caffeine (as model of POPs) and $\mathrm{Na}_{2} \mathrm{SO}_{4}$, used as supporting electrolyte $(0.035 \mathrm{M})$. In the CDEO experiment, the applied current density was $30 \mathrm{~mA} \mathrm{~cm}{ }^{-2}$. The ultrasound generator and ultraviolet lamp were used in continuous mode in the sonolysis (power irradiated $200 \mathrm{~W}$ ) and photolysis tests (power irradiated $4 \mathrm{~W}$ ), respectively.

The results show that CDEO allows for the efficient removal of the selected pollutants. The time required for electrolysis to completely remove the POPs (and thus, the requirements of electrical charge passed) varied with the type of pollutant studied, where SMX was the pollutant most efficiently degraded. In all cases, complete mineralisation occurred after 600 min of electrolysis (corresponding to $31 \mathrm{Ah} \mathrm{dm}^{-3}$ of electrical charge passed), except for the treatment of caffeine solution in which $800 \mathrm{~min}$ were required to attain the complete mineralisation. These good results are opposed to the very low extent of degradation achieved by photolysis and sonolysis, which also 
demonstrated a strong dependence on the type of molecule studied [29]. In the experiments carried out with caffeine, sonolysis and photolysis showed negligible degradation of the compound, whereas the extent of degradation of SMX by sonolysis was almost nil and greater than $25 \%$ by photolysis. In contrast, the extent of degradation of metoprolol ranged between 20 and $25 \%$ for each irradiation technology. With respect to the TOC profiles, no mineralisation due to sonolysis or photolysis was observed. This finding indicates that the raw pollutants were not complete degraded but partially oxidised. This leads to the formation of reaction intermediates due to the breakup of the molecules or even to the simple attack to any functional group by direct action of these irradiation techniques or by means of the oxidant agents generated. The degradation of these reaction intermediates to carbon dioxide as the final product is not favoured by any of the irradiation technologies.

The molecular structures of the three POPs studied in this work differ significantly (Table 1). In fact, metoprolol possesses alcohol or ether groups that may be quickly and easily attacked by the irradiation technologies employed. Likewise, SMX possesses sulphate and amino groups susceptible to oxidation by radicals generated during photolysis. This susceptibility may explain the higher rates of removal achieved for metoprolol and SMX by the irradiation technologies compared to the results obtained during the irradiation of wastewater polluted with caffeine, which has a much more complex molecular structure.

To better understand the performance of the three single-oxidation technologies, Figure 3 shows the changes in the intermediates (shown as chromatographic area due to the presence of unknown intermediates) observed during the degradation of SMX (part a), 
metoprolol (part b) and caffeine (part c) by photolysis, sonolysis and CDEO. The intermediates have been identified according to previous works of degradation of POPs by CDEO $[26,39,45]$.

As expected, in the CDEO experiments, the compounds formed during electrolysis showed typical intermediate behaviour (formation and further depletion during electrolysis). By contrast, the compounds formed during photolysis and sonolysis were accumulated in the reaction media and they remained in solution after 600 min of treatment. These results may explain the nil mineralisation observed in the latter cases due to the refractory behaviour of the species which behave final products. Moreover, it should be noted that the types of main intermediates formed during irradiation-assisted electrochemical technologies were different, indicating that the oxidation mechanisms involved in photolysis and sonolysis may differ.

Having demonstrated the high efficiency of CDEO compared with the efficiencies of the single-irradiation technologies, US and/or UV irradiation was coupled to the electrochemical oxidation system to study the removal of persistent pollutants by photoelectrolysis (Conductive Diamond Photo Electrochemical Oxidation, CDPEO), sonoelectrolysis (Conductive Diamond Sono Electrochemical Oxidation, CDSEO) and sono-photoelectrolysis (Conductive Diamond Sono Photo Electrochemical Oxidation, CDSPEO). Figure 4 shows the changes in the raw pollutant concentration (part a) and TOC (part b) during the treatment of wastewater polluted with SMX using these irradiation-assisted electrochemical technologies. For comparison, the results of single CDEO are also shown in the same figure. 
In comparing the results, it can be observed that initially $\left(\mathrm{Q}<2 \mathrm{Ah} \mathrm{dm}^{-3}\right)$, the concentration profiles overlapped, and, consequently, the removal efficiencies of SMX and TOC were similar for the different technologies studied. However, at higher applied electric charges, the POP concentration and TOC profiles became dependent on the technology used. As shown in the inset of Figure 4a, CDSEO is able to remove SMX with an electric charge of $10 \mathrm{Ah} \mathrm{dm}^{-3}$, lower than that (22 $\mathrm{Ah} \mathrm{dm}^{-3}$ ) required to completely deplete SMX via single CDEO. In contrast, UV irradiation (CDPEO and CDSPEO processes) had a negative effect, exhibiting lower efficiencies of SMX and TOC removal compared to those achieved by single CDEO, which can be due to an excessive formation of oxidant agents that instead of attacking organic species, are combined to form more stable and less aggressive oxidants, as will be explained later. On the other hand, as it can be observed in Figure 4b, TOC removals are slower than those of SMX, and this indicates that the degradation of SMX is not direct to carbon dioxide. In fact, several organic intermediates are detected in the reaction system during the electro-irradiated experiments.

Figure 5 shows the maximum concentration of the reaction intermediates formed during the treatment of wastewater polluted with SMX (concentration of each intermediate was normalised with respect to the maximum concentration attained by CDEO). A total of nine intermediates were identified during electrochemical degradation [30]. It can be clearly observed that irradiation with UV light led to a much lower concentration of intermediates; indeed, some intermediates were not even detected (suggesting that they were depleted rapidly after their formation) or they are formed in trace concentration (below detection limit of analytic technique used). This finding may suggest that the oxidation of SMX is slower under irradiation, but mineralisation is promoted. 
As is known, during the electrochemical oxidation of wastewater in sulphate media, the generation of peroxodisulphate occurs [37,31], which can promote the overall oxidation process (mediated oxidation). Likewise, it is reported that irradiated systems can favour the activation of peroxodisulphate to sulphate radical (Eq. 9). This radical species typically reacts $10^{3}-10^{5}$ times faster than persulphate anion [40], which can contribute to enhancing the pollutant-oxidation rate. According to Thomberg et al. [41], radical sulphate may be also formed slightly on the cathode by reduction of the peroxodisulphate.

$$
\mathrm{S}_{2} \mathrm{O}_{8}{ }^{2-} \stackrel{\text { hv } / \mathrm{US}}{\longrightarrow} 2\left(\mathrm{SO}_{4}^{-}\right)^{\bullet}
$$

In addition, the anodic production of hydroxyl radicals in CDEO [42] can be enhanced via reactions 10 and 11 , caused by the conversion to other oxidant species $\left(\mathrm{H}_{2} \mathrm{O}_{2}\right.$ and $\left.\mathrm{O}_{3}\right)$ under UV or US irradiation. In this case, in contrast to the results observed for a single electrolytic process, the effect of these radicals can be extended to the bulk phase, significantly improving the removal efficiency.

$$
\begin{aligned}
& \mathrm{H}_{2} \mathrm{O}_{2} \stackrel{\text { hv/US }}{\longrightarrow} 2{ }^{\bullet} \mathrm{OH} \\
& \mathrm{H}_{2} \mathrm{O}_{2}+\mathrm{O}_{3} \stackrel{\text { hv } / \text { Us }}{\longrightarrow} 2{ }^{\bullet} \mathrm{OH}+\mathrm{O}_{2}
\end{aligned}
$$

Taking into account the possibility of oxidant activation in the bulk, in single CDEO, SMX and intermediates are expected to be completely depleted near the electrode surface, whereas in CDPEO, bulk oxidation is expected [43,29,15,16,19]. The higher concentration of intermediates measured in CDSEO suggests that this technology mainly favours improvements in the mass transfer of pollutants (hence, organics are expected to be oxidised near the electrode surface, as in single CDEO). 
For further comparison, a kinetics analysis was carried out. As is known, the oxidation of organics by US or UV irradiation can be well fitted to a pseudo-first order kinetic model, where the kinetic constant depends on the energy irradiated. For electrochemical oxidation processes, the first-order model also performs well, and in this case, the kinetic constant is related to the mass transfer coefficient and to the kinetic constants of the various mediated oxidation processes that may coexist [26,39,44,45]. In view of these observations, Figures 6 and 7 show the pseudo-first order kinetic constants calculated in terms of pollutant and TOC removal, respectively, for the removal of the three POPs studied in this work. This figure also compares these kinetic constants with the values expected according to the addition of the different single contributions. This comparison was carried out to determine the existence of a synergist or antagonist in the application of the coupled technologies.

In comparing results, significant differences between the kinetic constants calculated for the raw pollutant and TOC can be observed. It should be noted that the first parameter represents only for the first stage of oxidation; the second is the more important parameter because it provides information on the overall process. In terms of pollutant degradation, the calculated values indicate a very strong effect of pollutant type on the degradation process. Synergistic effects are clearly observed for the oxidation of caffeine using CDSEO, CDPEO and CDSPEO (Figure 6c) and for the oxidation of SMX and metoprolol by CDSEO (Figures 6a and 6b). By contrast, for the two latter pollutants, it can be observed that coupling UV irradiation to electrolysis leads to worse results than those expected by the addition of the constants of the two single 
technologies. As previously suggested, these results only indicate the susceptibility of the raw pollutant to rapid oxidation; they are not a reliable process indicator.

A more reliable indicator is expected to be the mineralisation (TOC removal) kinetic constant because it is related to the complete treatment process. In comparing the kinetic constants calculated in terms of mineralisation attained (Figure 7), it can be observed that coupling UV light and/or US irradiation to the electrochemical oxidation of SMX does not provide a significant improvement in the mineralisation rate; in fact, certain antagonistic effects can be discerned. Moreover, in the metoprolol degradation experiments, a significant improvement was observed only when sono-irradiated techniques were used, whereas CDSPEO was the optimal technology for efficient mineralisation in the treatment of wastewater contaminated with caffeine.

Hence, coupling US and/or UV to CDEO irradiation does not always lead to an improvement in the process performance, in spite of favouring the activation of oxidants in the bulk phase. Unfortunately, this coupling may also lead to losses of oxidation efficiency. To explain this unexpected antagonistic behaviour, it must be considered that in the application of coupled irradiation-assisted electrochemical technologies, an excessive formation of radicals may occur. In such cases, instead of attacking organic species, the radicals may combine to form more stable and less aggressive oxidants or even decompose oxygen that may be forming [29,28] according to Eq. 12-16:

$$
\begin{aligned}
& 2^{\bullet} \mathrm{OH} \rightarrow \mathrm{H}_{2} \mathrm{O}_{2} \\
& \bullet \mathrm{OH}+\left(\mathrm{SO}_{4}^{-}\right)^{\bullet} \rightarrow \mathrm{HSO}_{5}^{-} \\
& \mathrm{H}_{2} \mathrm{O}_{2} \rightarrow \mathrm{H}_{2} \mathrm{O}+0.5 \mathrm{O}_{2} \\
& \mathrm{HSO}_{5}^{-} \rightarrow \mathrm{HSO}_{4}^{-}+0.5 \mathrm{O}_{2}
\end{aligned}
$$




$$
\mathrm{HSO}_{4}{ }^{-}+{ }^{\bullet} \mathrm{OH} \rightarrow \mathrm{SO}_{4}{ }^{2-}+\mathrm{H}_{2} \mathrm{O}
$$

These reactions may compete with the oxidation of pollutants, which explains the strong effect of pollutant type on the results. A great advantage of US irradiation is that in addition to the promotion oxidant decomposition, it generates turbulent conditions in the medium by the implosion of generated microbubbles. This turbulence improves the transfer of organic species to the anodic surface, where they can be oxidised directly or through a mediated by oxidising agents near this surface [12,13,22,23]. Differences due to the nature of the initial pollutant are difficult to explain in terms of mass transfer limitations and may indicate that mediated oxidation processes also play a very important role in the overall degradation of any POPs. Furthermore, this uncertainty suggests that the synergism or antagonism of coupling US and UV irradiation to CDEO cannot currently be predicted; thus, further studies should be carried out to clarify the relationship between pollutant type and these effects.

\section{Conclusions}

Based on the results of this study, the following conclusions can be drawn:

- CDEO can significantly reduce the presence of persistent compounds such as SMX, metoprolol and caffeine, removing not only the compound itself but also the intermediates formed.

- Single-sonolysis and single-photolysis technologies only entail a slight removal of the aforementioned pollutants and nil mineralisation, forming reaction intermediates whose removal is prevented.

- The combined use of irradiation techniques (US or UV light) and electrochemical oxidation improves the degradation rate of POPs, but the 
efficiency thereof depends on the nature of the initial pollutant, indicating the important role played by mediated oxidation in the overall oxidation process.

\section{Acknowledgements}

The authors acknowledge funding support from the Spanish Government (Project CTM2013-45612-R). The FPU scholarship awarded to María Jose Martín de Vidales is also gratefully acknowledged. 


\section{Figure Captions}

Figure 1. Experimental set-up. 1. Glass tank. 2. Peristaltic pump. 3. Electrolytic cell. 4. UV lamp. 5. Heat exchanger. 6. Power supply. 7. US generator. Onset (UV reactor): 8. Anode (BDD). 9. Lattice cathode (stainless steel). 10. Quartz plate.

Figure 2. Time course of POP concentration and TOC for the experiments carried out by photolysis (a), sonolysis (b) and CDEO (c). [Pollutant] $]_{0}: 100 \mathrm{mg} \mathrm{dm}^{-3}, \mathrm{j}: 30 \mathrm{~mA} \mathrm{~cm}^{-2}$, $0.035 \mathrm{M} \mathrm{Na}_{2} \mathrm{SO}_{4}$. Ultrasonic wave: continuous mode/200 W. Ultraviolet light: $254 \mathrm{~nm} / 4$

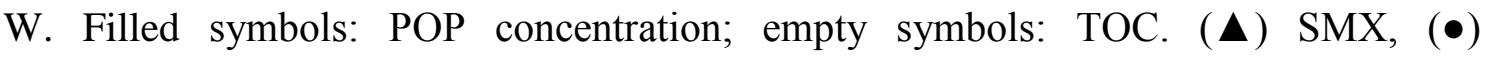
metoprolol, ( $\diamond$ ) caffeine.

Figure 3. Chromatographic area profiles of the reaction intermediates observed in studies of wastewaters polluted with SMX (a), metoprolol (b) and caffeine (c) and oxidised by photolysis (empty symbols), sonolysis (grey symbols) and CDEO (full symbols). [Pollutant] $0: 100 \mathrm{mg} \mathrm{dm}^{-3}$, j: $30 \mathrm{~mA} \mathrm{~cm}{ }^{-2}, 0.035 \mathrm{M} \mathrm{Na}_{2} \mathrm{SO}_{4}$. Ultrasonic wave: continuous mode/200 W. Ultraviolet light: $254 \mathrm{~nm} / 4 \mathrm{~W}$. SMX study: (匹) $\mathrm{C}_{10} \mathrm{H}_{11} \mathrm{~N}_{3} \mathrm{O}_{4} \mathrm{~S}$,

$(\bullet) \mathrm{C}_{6} \mathrm{H}_{4} \mathrm{O}_{2},(\boldsymbol{\Delta}) \mathrm{C}_{4} \mathrm{H}_{6} \mathrm{~N}_{2} \mathrm{O},(\bullet) \mathrm{C}_{6} \mathrm{H}_{5} \mathrm{NO}_{5} \mathrm{~S},(-) \mathrm{C}_{7} \mathrm{H}_{5} \mathrm{~N}_{3} \mathrm{O}_{4} \mathrm{~S},(-) \mathrm{C}_{7} \mathrm{H}_{7} \mathrm{NO}_{3} \mathrm{~S}$, (*) $\mathrm{C}_{10} \mathrm{H}_{13} \mathrm{~N}_{3} \mathrm{O}_{5} \mathrm{~S}$, (+) $\mathrm{C}_{6} \mathrm{H}_{8} \mathrm{~N}_{2} \mathrm{O}_{2} \mathrm{~S}$, (x) $\mathrm{C}_{7} \mathrm{H}_{7} \mathrm{~N}_{3} \mathrm{O}_{2}$. Metoprolol study: (ロ) $\mathrm{i}_{1}$, (•) $\mathrm{i}_{2}$. Caffeine study: (ロ) $\mathrm{C}_{6} \mathrm{H}_{8} \mathrm{~N}_{2} \mathrm{O}_{5},(\bullet) \mathrm{C}_{6} \mathrm{H}_{9} \mathrm{~N}_{3} \mathrm{O}_{4},(\boldsymbol{\Delta}) \mathrm{i}_{1}$.

Figure 4. SMX concentration (a) and TOC (b) profiles for the experiments carried out by $\operatorname{CDEO}(\boldsymbol{\bullet}), \operatorname{CDSEO}(\Delta), \operatorname{CDPEO}(\boldsymbol{\Delta})$ and $\operatorname{CDSPEO}(\circ) .\left[\mathrm{SMX}_{0}: 100 \mathrm{mg} \mathrm{dm}{ }^{-3}, \mathrm{j}: 30\right.$ mA cm${ }^{-2}, 0.035 \mathrm{M} \mathrm{Na}_{2} \mathrm{SO}_{4}$. Ultrasonic wave: continuous mode/200 W. Ultraviolet light: $254 \mathrm{~nm} / 4 \mathrm{~W}$. Inset: scale expansion. 
Figure 5. Concentration of the reaction intermediates (normalised with respect to the maximum concentration attained by CDEO) formed during the irradiation-assisted electrochemical treatment of wastewater polluted with SMX. $[\mathrm{SMX}]_{0}: 100 \mathrm{mg} \mathrm{dm}^{-3}$, j: $30 \mathrm{~mA} \mathrm{~cm}{ }^{-2}, 0.035 \mathrm{M} \mathrm{Na}_{2} \mathrm{SO}_{4}$. Ultrasonic wave: continuous mode/200 W. Ultraviolet

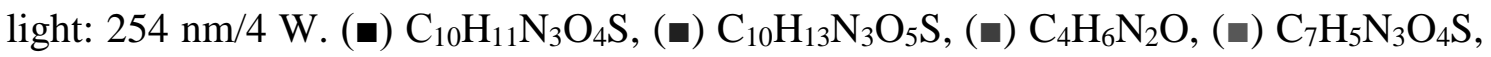
( $\square) \mathrm{C}_{6} \mathrm{H}_{8} \mathrm{~N}_{2} \mathrm{O}_{2},(/) \mathrm{C}_{7} \mathrm{H}_{7} \mathrm{~N}_{3} \mathrm{O}_{2} \mathrm{~S}$, (x) $\mathrm{C}_{7} \mathrm{H}_{7} \mathrm{NO}_{3} \mathrm{~S}$, ( $\left(\right.$ ) $\mathrm{C}_{6} \mathrm{H}_{5} \mathrm{NO}_{5} \mathrm{~S}$, ( $\left.\square\right) \mathrm{C}_{6} \mathrm{H}_{4} \mathrm{O}_{2}$.

Figure 6. Kinetic constants calculated in terms of pollutant removal for the different processes and comparison with the values calculated by the addition of the different single contributions. Studies of the degradation of SMX (a), metoprolol (b), and caffeine (c).

Figure 7. Kinetic constants calculated in terms of TOC removal for the different processes and comparison with the values calculated by the addition of the different single contributions. Studies of the degradation of SMX (a), metoprolol (b) and caffeine (c). 


\section{References}

1. Esplugas S, Bila DM, Krause LGT, Dezotti M (2007) Ozonation and advanced oxidation technologies to remove endocrine disrupting chemicals (EDCs) and pharmaceuticals and personal care products (PPCPs) in water effluents. Journal of Hazardous Materials 149 (3):631642

2. Ternes TA (1998) Occurrence of drugs in German sewage treatment plants and rivers. Water Research 32 (11):3245-3260

3. Brillas E, Boye B, Sirés I, Garrido JA, Rodríguez RM, Arias C, Cabot PL, Comninellis C (2004) Electrochemical destruction of chlorophenoxy herbicides by anodic oxidation and electroFenton using a boron-doped diamond electrode. Electrochimica Acta 49 (25):4487-4496 4. Brillas E, Garcia-Segura S, Skoumal M, Arias C (2010) Electrochemical incineration of diclofenac in neutral aqueous medium by anodic oxidation using $\mathrm{Pt}$ and boron-doped diamond anodes. Chemosphere 79 (6):605-612

5. Abdessamad N, Akrout H, Hamdaoui G, Elghniji K, Ksibi M, Bousselmi L (2013) Evaluation of the efficiency of monopolar and bipolar BDD electrodes for electrochemical oxidation of anthraquinone textile synthetic effluent for reuse. Chemosphere 93 (7):1309-1316

6. Daskalaki VM, Marakas H, Mantzavinos D, Katsaounis A, Gikas P (2013) Use of seawater for the boron-doped diamond electrochemical treatment of diluted vinasse wastewater. Water Science and Technology 68 (11):2344-2350

7. Steter JR, Rocha RS, Dionísio D, Lanza MRV, Motheo AJ (2014) Electrochemical oxidation route of methyl paraben on a boron-doped diamond anode. Electrochimica Acta 117:127-133

8. Cavalcanti EB, Garcia-Segura S, Centellas F, Brillas E (2013) Electrochemical incineration of omeprazole in neutral aqueous medium using a platinum or boron-doped diamond anode:

Degradation kinetics and oxidation products. Water Research 47 (5):1803-1815

9. Polcaro AM, Mascia M, Palmas S, Vacca A (2004) Electrochemical degradation of diuron and dichloroaniline at BDD electrode. Electrochimica Acta 49 (4):649-656

10. Boye B, Brillas E, Marselli B, Michaud PA, Comninellis C, Farnia G, Sandonà G (2006)

Electrochemical incineration of chloromethylphenoxy herbicides in acid medium by anodic oxidation with boron-doped diamond electrode. Electrochimica Acta 51 (14):2872-2880

11. Wang J, Li X (2012) Electrochemical treatment of wastewater containing chlorophenols using boron-doped diamond film electrodes. Advanced Materials Research, vol 356-360.

12. Lorimer JP, Mason TJ, Plattes M, Phull SS, Iniesta J, Walton DJ (2004) Sonovoltammetric studies on copper in buffered alkaline solution. Ultrasonics Sonochemistry 11 (3-4):223-226 13. Flannigan DJ, Suslick KS (2005) Plasma formation and temperature measurement during single-bubble cavitation. Nature 434 (7029):52-55

14. Osugi ME, Umbuzeiro GA, Anderson MA, Zanoni MVB (2005) Degradation of metallophtalocyanine dye by combined processes of electrochemistry and photoelectrochemistry. Electrochimica Acta 50 (25-26 SPEC. ISS.):5261-5269 15. Pinhedo L, Pelegrini R, Bertazzoli R, Motheo AJ (2005) Photoelectrochemical degradation of humic acid on a (TiO2) 0.7(RuO2)0.3 dimensionally stable anode. Applied Catalysis B:

Environmental 57 (2):75-81

16. Catanho M, Malpass GRP, Motheo AJ (2006) Photoelectrochemical treatment of the dye reactive red 198 using DSA ${ }^{\circledR}$ electrodes. Applied Catalysis B: Environmental 62 (3-4):193-200 17. Li G, Qu J, Zhang X, Ge J (2006) Electrochemically assisted photocatalytic degradation of Acid Orange 7 with $\beta$-PbO2 electrodes modified by TiO2. Water Research 40 (2):213-220 18. Socha A, Sochocka E, Podsiadły R, Sokołowska J (2006) Electrochemical and photoelectrochemical degradation of direct dyes. Coloration Technology 122 (4):207-212 19. Socha A, Sochocka E, Podsiadły R, Sokołowska J (2007) Electrochemical and photoelectrochemical treatment of C.I. Acid Violet 1. Dyes and Pigments 73 (3):390-393 
20. Sánchez-Carretero A, Rodrigo MA, Cañizares P, Sáez C (2010) Electrochemical synthesis of ferrate in presence of ultrasound using boron doped diamond anodes. Electrochemistry Communications 12 (5):644-646

21. de Freitas AM, Sirtori C, Peralta-Zamora P (2011) Photoelectrocatalytic degradation of camphor on TiO2/RuO2 electrodes. Environmental Chemistry Letters 9 (1):97-102

22. Sánchez-Carretero A, Sáez C, Cañizares P, Cotillas S, Rodrigo MA (2011) Improvements in the electrochemical production of ferrates with conductive diamond anodes using goethite as raw material and ultrasound. Industrial and Engineering Chemistry Research 50 (11):7073-7076 23. Rooze J, Rebrov EV, Schouten JC, Keurentjes JTF (2013) Dissolved gas and ultrasonic cavitation - A review. Ultrasonics Sonochemistry 20 (1):1-11

24. Polar JA (2007) The fate of pharmaceuticals after wastewater treatment. Florida Water Resources J:26-31

25. Cañizares P, Paz R, Lobato J, Sáez C, Rodrigo MA (2006) Electrochemical treatment of the effluent of a fine chemical manufacturing plant. Journal of Hazardous Materials 138 (1):173181

26. Indermuhle C, Martín de Vidales MJ, Sáez C, Robles J, Cañizares P, García-Reyes JF, MolinaDíaz A, Comninellis C, Rodrigo MA (2013) Degradation of caffeine by conductive diamond electrochemical oxidation. Chemosphere 93 (9):1720-1725

27. Martín de Vidales MJ, Sáez C, Cañizares P, Rodrigo MA (2013) Removal of triclosan by conductive-diamond electrolysis and sonoelectrolysis. Journal of Chemical Technology and Biotechnology 88 (5):823-828

28. Vidales MJMD, Barba S, Sáez C, Cañizares P, Rodrigo MA (2014) Coupling ultraviolet light and ultrasound irradiation with Conductive-Diamond Electrochemical Oxidation for the removal of progesterone. Electrochimica Acta 140:27-32

29. Souza FL, Sáez C, Cañizares P, Motheo AJ, Rodrigo MA (2013) Coupling photo and sono technologies to improve efficiencies in conductive diamond electrochemical oxidation. Applied Catalysis B: Environmental 144 (1):121-128

30. Pelegrini R, Peralta-Zamora P, De Andrade AR, Reyes J, Durán N (1999) Electrochemically assisted photocatalytic degradation of reactive dyes. Applied Catalysis B: Environmental 22 (2):83-90

31. Serrano K, Michaud PA, Comninellis C, Savall A (2002) Electrochemical preparation of peroxodisulfuric acid using boron doped diamond thin film electrodes. Electrochimica Acta 48 (4):431-436

32. Wang J, Farrell J (2004) Electrochemical inactivation of triclosan with boron doped diamond film electrodes. Environmental Science and Technology 38 (19):5232-5237 33. Polcaro AM, Vacca A, Mascia M, Ferrara F (2008) Product and by-product formation in electrolysis of dilute chloride solutions. Journal of Applied Electrochemistry 38 (7):979-984 34. Murata M, Ivandini TA, Shibata M, Nomura S, Fujishima A, Einaga Y (2008) Electrochemical detection of free chlorine at highly boron-doped diamond electrodes. Journal of Electroanalytical Chemistry 612 (1):29-36

35. Bergmann MEH, Rollin J, lourtchouk T (2009) The occurrence of perchlorate during drinking water electrolysis using BDD anodes. Electrochimica Acta 54 (7):2102-2107

36. Sánchez A, Llanos J, Sáez C, Cañizares P, Rodrigo MA (2013) On the applications of peroxodiphosphate produced by BDD-electrolyses. Chemical Engineering Journal 233:8-13 37. Cañizares P, Lobato J, Paz R, Rodrigo MA, Sáez C (2005) Electrochemical oxidation of phenolic wastes with boron-doped diamond anodes. Water Research 39 (12):2687-2703 38. Coñizares P, García-Gómez J, Fernández de Marcos I, Rodrigo MA, Lobato J (2006) Measurement of mass-transfer coefficients by an electrochemical technique. Journal of Chemical Education 83 (8):1204-1207

39. Martín de Vidales MJ, Robles-Molina J, Domínguez-Romero JC, Cañizares P, Sáez C, MolinaDíaz A, Rodrigo MA (2012) Removal of sulfamethoxazole from waters and wastewaters by 
conductive-diamond electrochemical oxidation. Journal of Chemical Technology and Biotechnology 87 (10):1441-1449

40. Tsitonaki A, Petri B, Crimi M, Mosbk H, Siegrist RL, Bjerg PL (2010) In situ chemical oxidation of contaminated soil and groundwater using persulfate: A review. Critical Reviews in Environmental Science and Technology 40 (1):55-91

41. Thomberg T, Nerut J, Jäger R, Möller P, Lust K, Lust E (2005) The kinetics of electroreduction of peroxodisulfate ions on single crystal cadmium and bismuth electrodes. Journal of Electroanalytical Chemistry 582 (1-2):130-143

42. Marselli B, Garcia-Gomez J, Michaud PA, Rodrigo MA, Comninellis C (2003)

Electrogeneration of hydroxyl radicals on boron-doped diamond electrodes. Journal of the Electrochemical Society 150 (3):D79-D83

43. Souza FL, Aquino JM, Miwa DW, Rodrigo MA, Motheo AJ (2014) Photo-assisted electrochemical degradation of the dimethyl phthalate ester on $D A^{\circledast}$ electrode. Journal of Environmental Chemical Engineering 2 (2):811-818

44. Martín de Vidales MJ, Sáez C, Cañizares P, Rodrigo MA (2012) Electrolysis of progesterone with conductive-diamond electrodes. Journal of Chemical Technology and Biotechnology 87

(8):1173-1178

45. Martín de Vidales MJ, Sáez C, Cañizares P, Rodrigo MA (2012) Metoprolol abatement from wastewaters by electrochemical oxidation with boron doped diamond anodes. Journal of Chemical Technology and Biotechnology 87 (2):225-231 
Table 1. Molecular structure of the POPs studied.

\begin{tabular}{c|cc}
\hline POP & Molecular formula & Molecular structure \\
\hline Sulfamethoxazole & $\mathrm{C}_{10} \mathrm{H}_{11} \mathrm{~N}_{3} \mathrm{O}_{3} \mathrm{~S}$ \\
Caffeine & $\left(\mathrm{C}_{15} \mathrm{H}_{25} \mathrm{NO}_{3}\right)_{2} \cdot \mathrm{C}_{4} \mathrm{H}_{6} \mathrm{O}_{6}$ \\
$\mathrm{C}_{8} \mathrm{H}_{10} \mathrm{~N}_{4} \mathrm{O}_{2}$ &
\end{tabular}




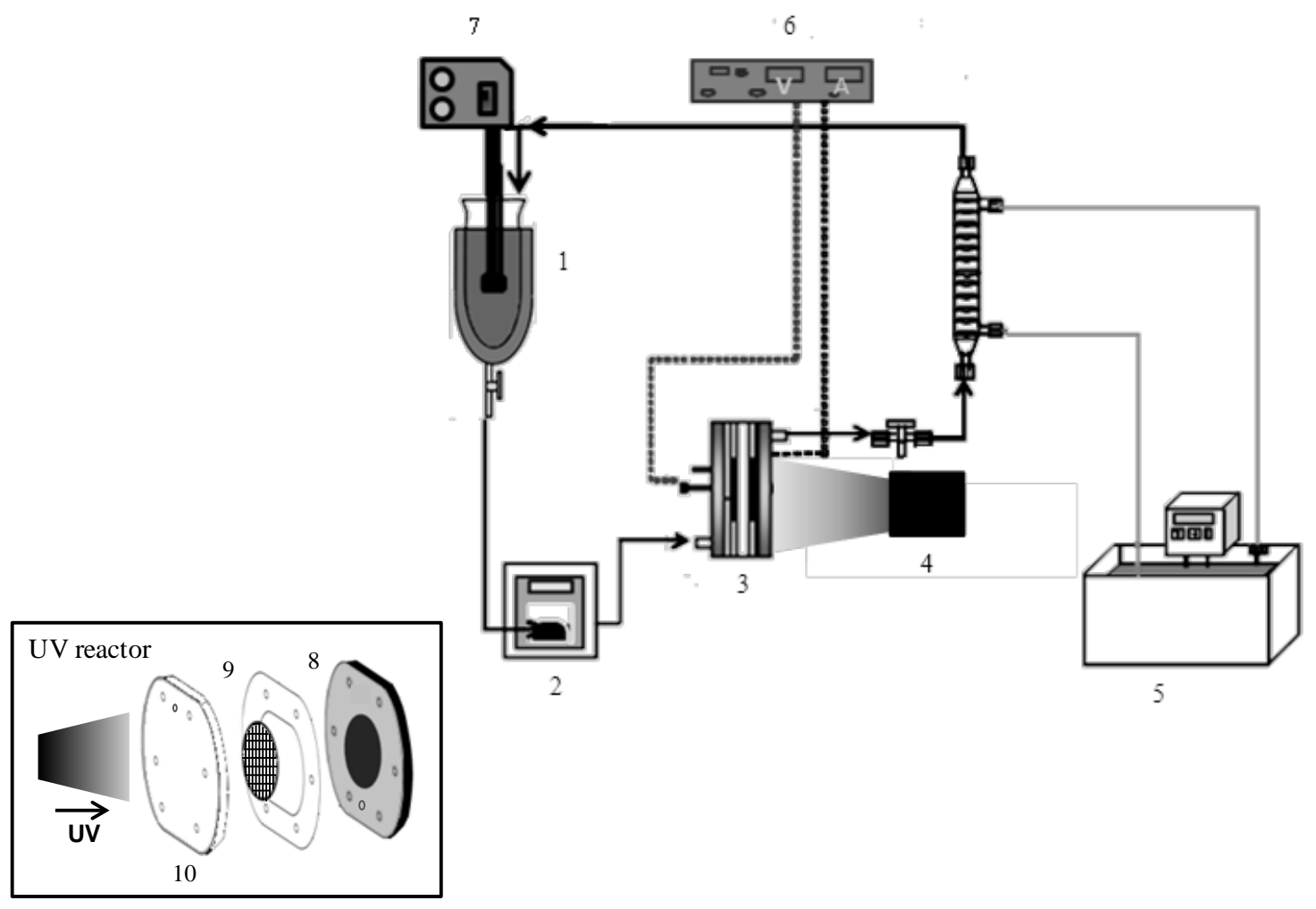

Figure 1 

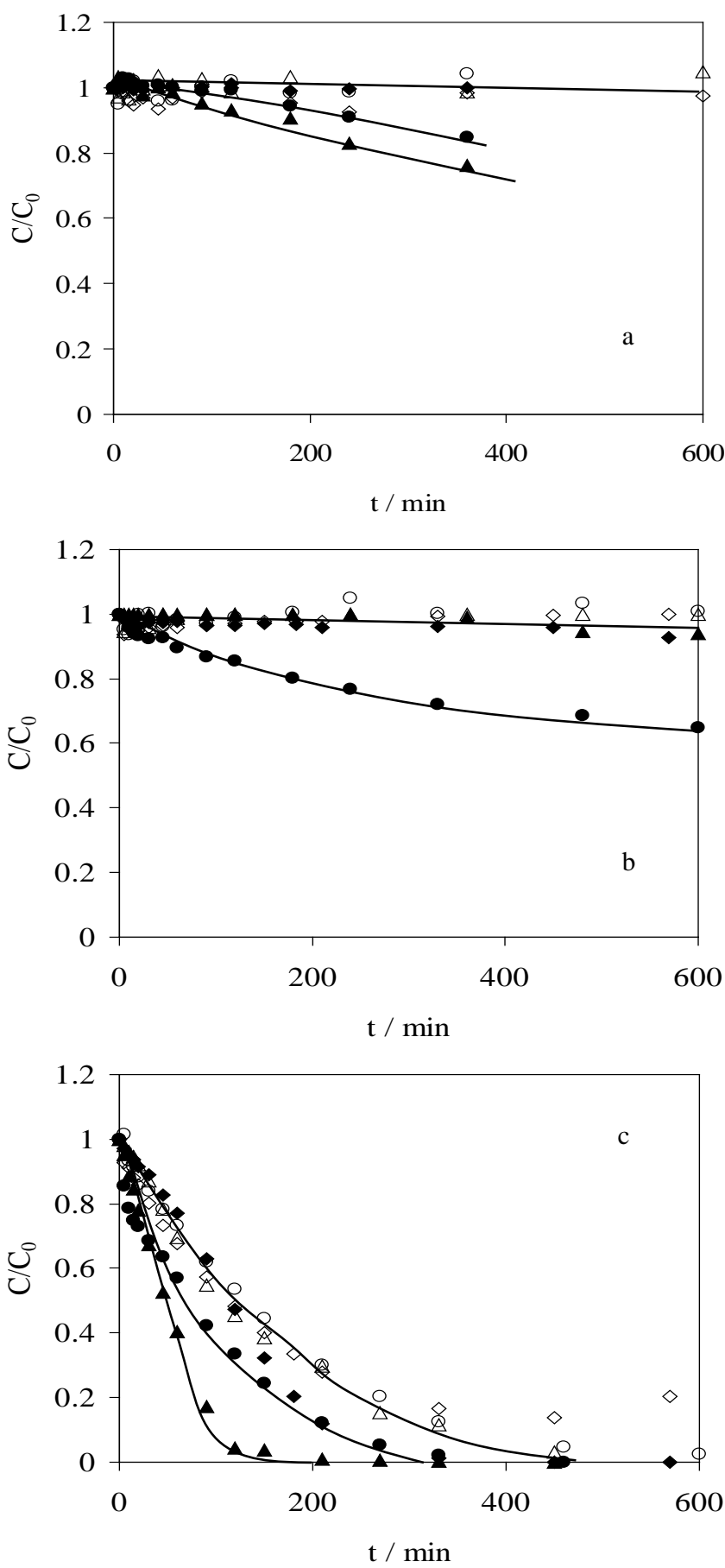

Figure 2 

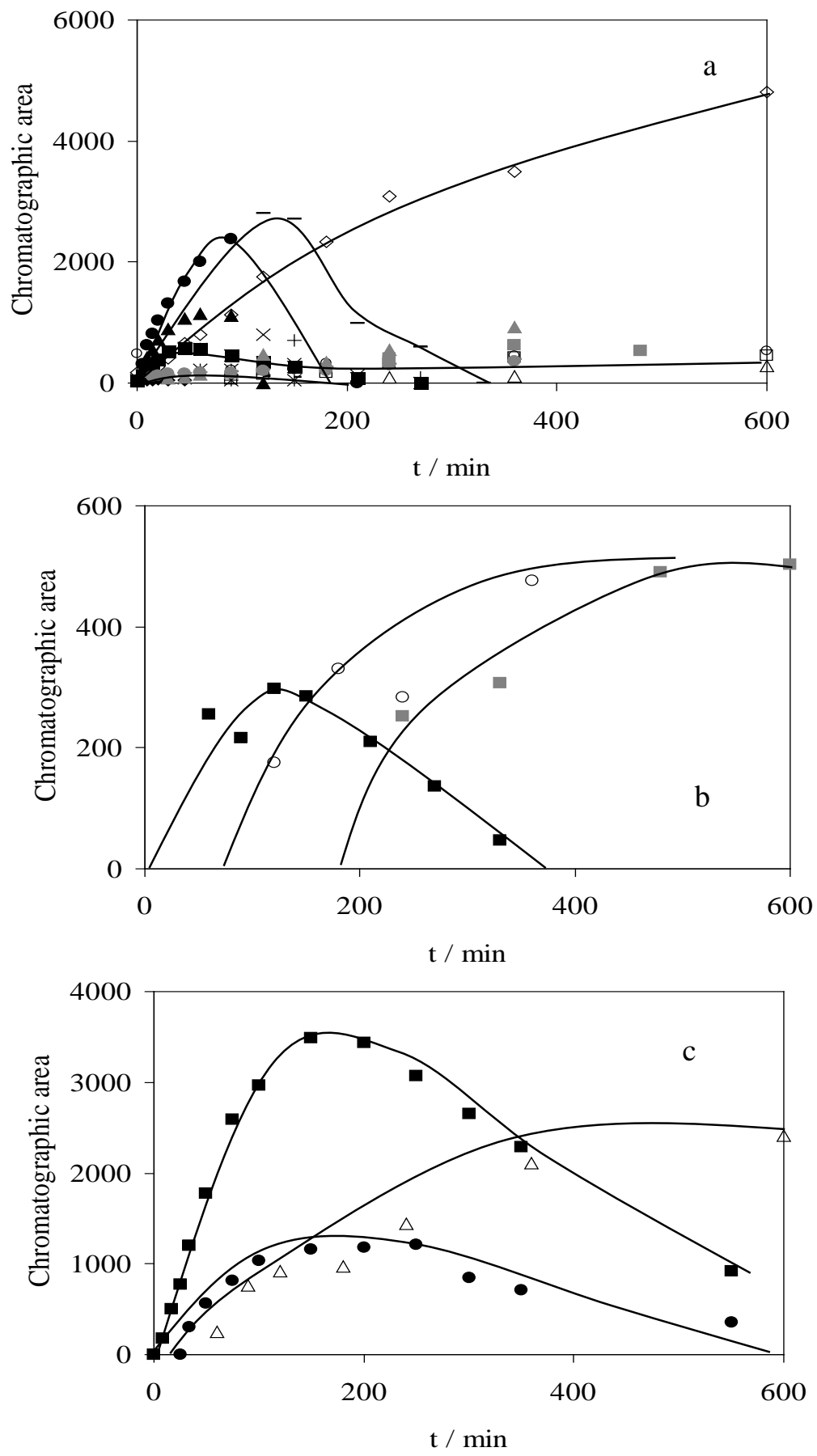

Figure 3 

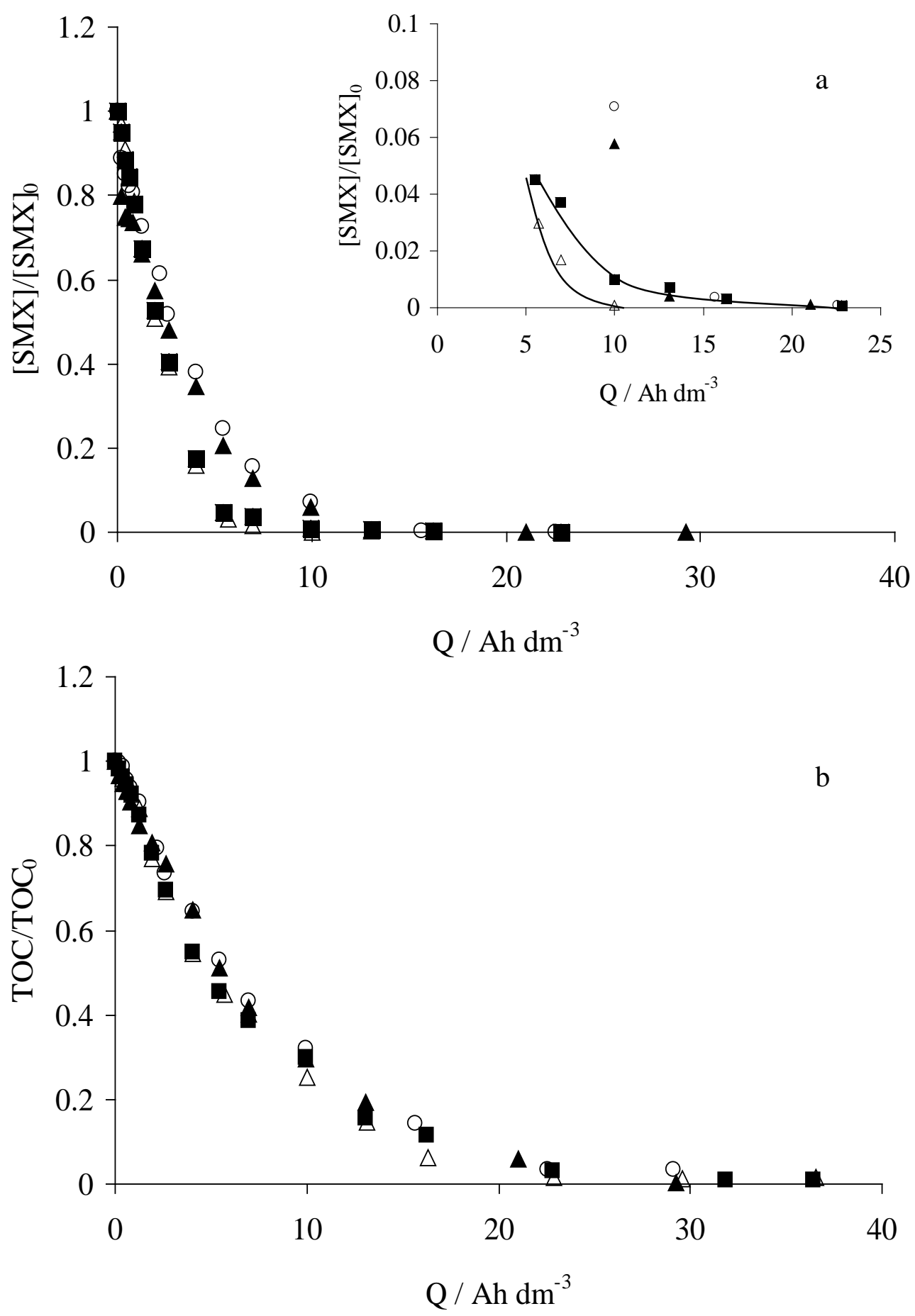

Figure 4 


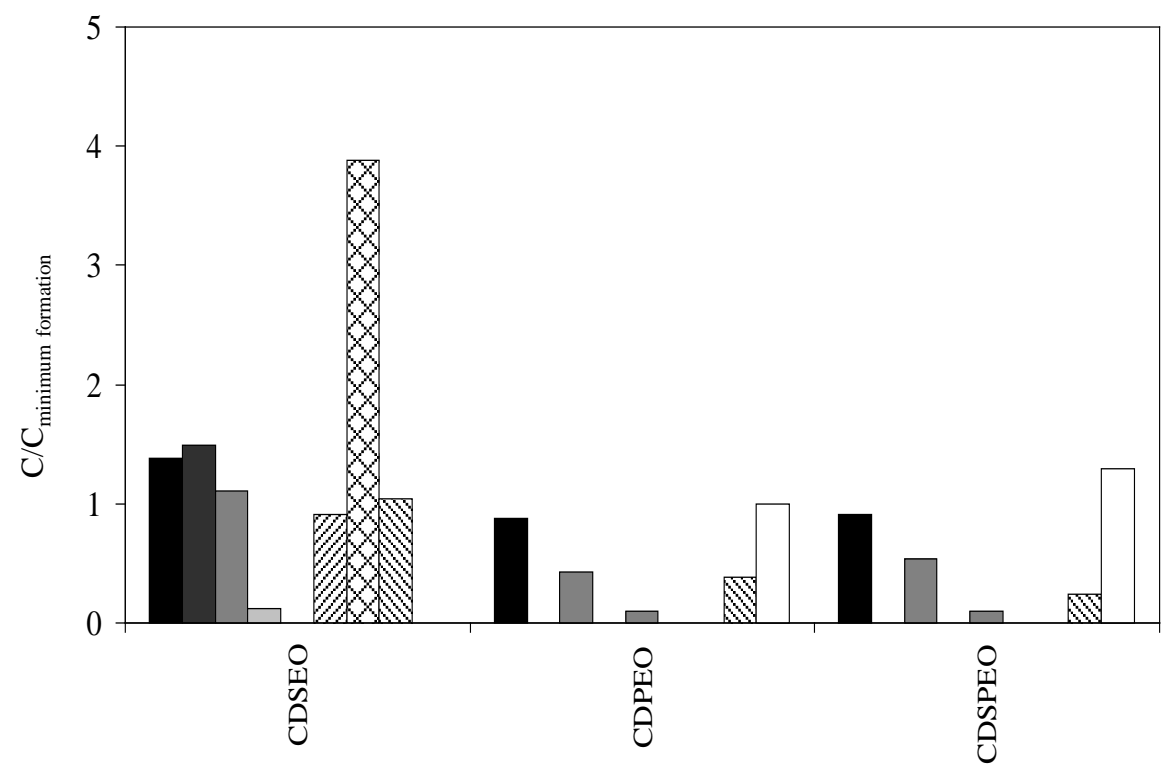

Figure 5 

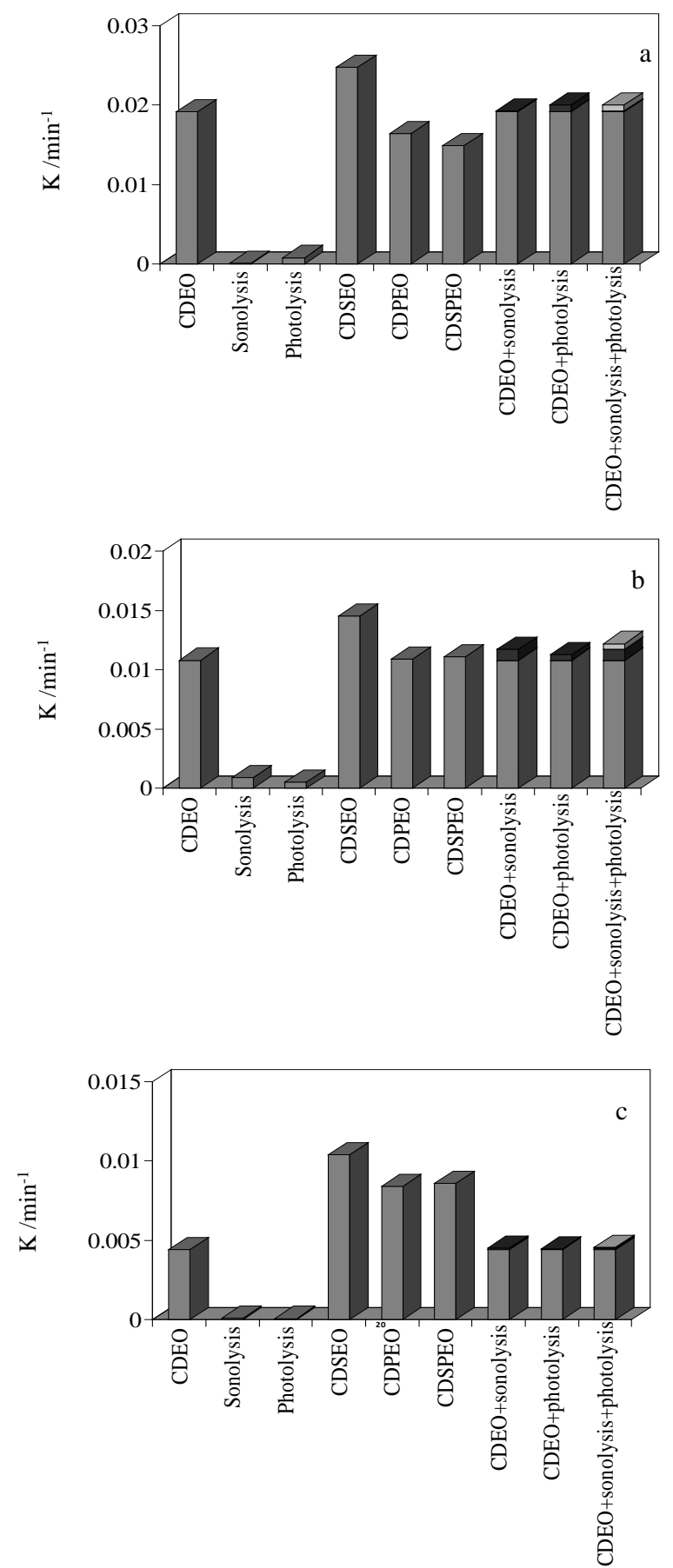

Figure 6 

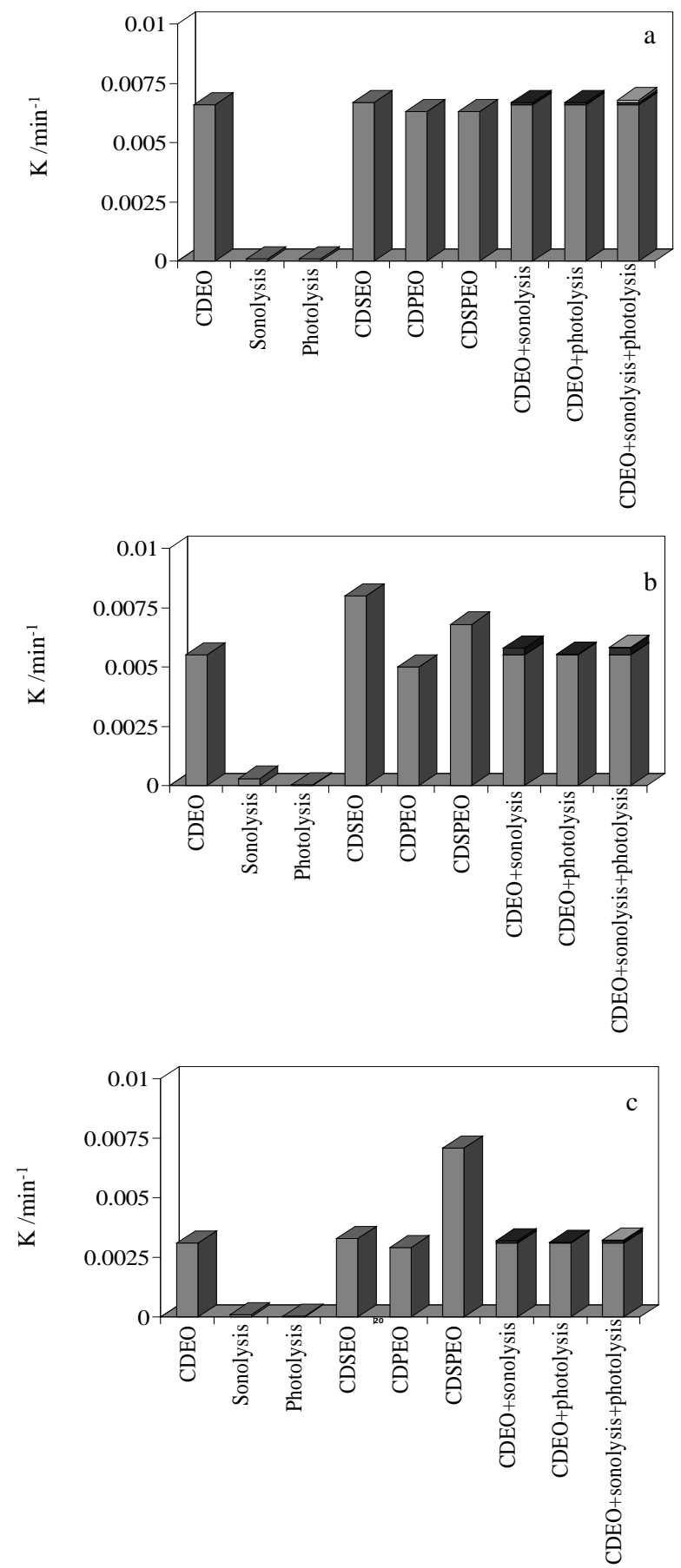

Figure 7 